\title{
Xanthogranulomatous Prostatitis Presenting as a Prostatic Abscess: Case Report and Review of Literature
}

\author{
Purnendu Majumdar ${ }^{\text {a, }}$, Stephen McSorley ${ }^{\mathrm{a}}$, Imran Ahmad ${ }^{\mathrm{a}}$, Ian B. Dunn ${ }^{\mathrm{a}}$
}

\begin{abstract}
Xanthogranulomatous inflammation of the prostate presenting as a prostatic abscess is rare, and we present what we believe to be only the second such case report in the literature. A review of literature related to prostatic abscess as well as xanthogranulomatous inflammation in general is also presented.
\end{abstract}

Keywords: Prostatic abscess; Xanthogranulomatous inflammation; Differential diagnosis

\section{Introduction}

The exact aetiology of a xanthogranulomatous type of inflammation is unknown. Different organs may be affected, and pathologically there is tissue destruction along with an infiltrate of plasma cells and lymphocytes, surrounded by typically foamy (lipid-laden) macrophages [1]. Clinically it may mimic prostate malignancy.

Immunosuppression, diabetes as well as urethral instrumentation are important predisposing factors in patients developing prostatic abscess. Drainage of prostatic abscesses can be achieved either by transurethral resection (TURP) or percutaneous/transrectal needle aspiration.

\section{Case Report}

A 65-year-old Caucasian gentleman with type II Diabetes

\footnotetext{
Manuscript accepted for publication May 3, 2013

${ }^{a}$ Department of Urology, Monklands District General Hospital, Monkscourt Avenue, Airdrie, North Lanarkshire, ML6 0JS, United Kingdom

${ }^{\mathrm{b}}$ Corresponding author: Purnendu Majumdar, Department of Urology, Monklands District General Hospital, Monkscourt Avenue, Airdrie, ML6 0JS, United Kingdom. Email: pmajum@aol.com
}

doi: http://dx.doi.org/10.4021/wjnu89w
Mellitus and a long standing history of psoriasis and psoriatic arthropathy presented to the medical unit with sepsis of unknown origin. He had been on Methotrexate treatment for many years and was recently started on Infliximab infusions which controlled his painful arthropathy. This was later changed to Etanercept because of poor venous access. Since starting the immuno-suppressants he developed a chest infection and also had storage type of LUTS. PSA was normal. Subsequently, after developing signs of recurrent lower urinary tract infections, he was treated in the community with nitrofurantoin for a Staph. aureus urinary infection. Urine cultures for AFB were negative.

Three months later he was admitted on the medical ward with recurrent pyrexia and UTI. Urine culture showed no growth on admission. Although a blood culture on admission showed a first isolation of Staph. aureus, there was no growth after 5 days. He was treated with ciprofloxacin initially, later changed to Daptomycin based on culture report. MRSA was not isolated. After the three episodes of urinary retention and persistent pyrexia despite antibiotics over a period of 4 weeks, he had an abdomino-pelvic CT scan. This showed a large intra-prostatic abscess (Fig. 1), following which a urological opinion was sought. Clinically he had intense perineal discomfort, and on digital rectal examination the prostate felt considerably enlarged and fluctuant. We undertook an urgent trans-urethral resection and de-roofing of this abscess. Copious amount of pus was drained and the patient showed rapid improvement in clinical parameters. Tissue cultures were negative but histology showed xanthogranulomatous prostatitis, without any evidence of malignancy (Fig. 2). Despite good voiding parameters, the postoperative course was delayed by intractable hiccoughs; no cause was found despite thorough investigations. Another scan undertaken during this period showed complete resolution of the prostatic abscess (Fig. 3).

A few weeks later patient again presented with UTIs, and left testicular pain and swelling, with urine cultures showing Staph. aureus, (MRSA not seen). Flow rates were non-obstructed. After a couple of weeks of ineffective antibiotic therapy and further aggravation of his painful, swollen left testis, he underwent a left orchidectomy, following which his symptoms resolved. Histology of the testis showed 


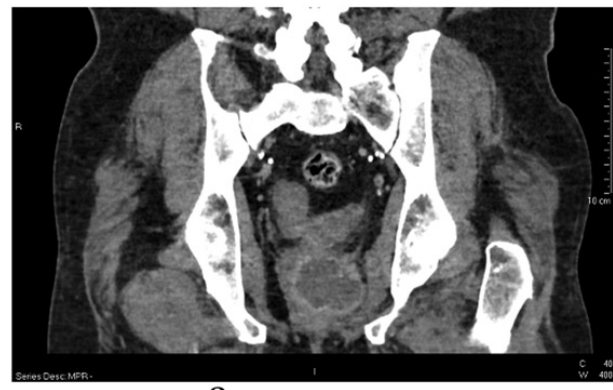

a

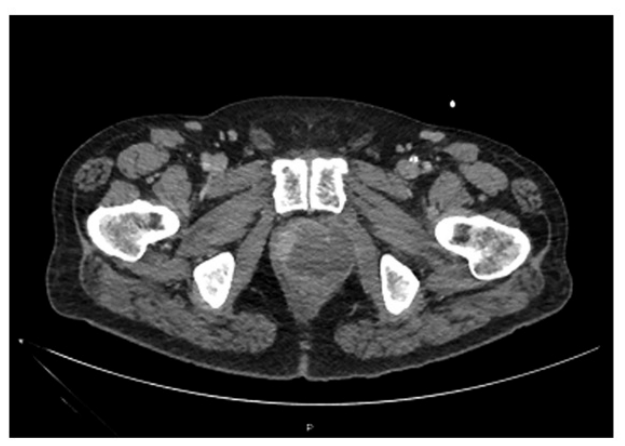

C

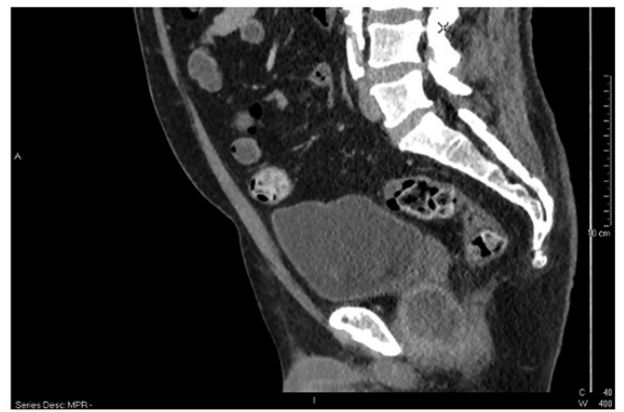

b

Figure 1. Prostatic abscess: appearance on CT prior to trans-urethral resection and drainage in coronal (a), sagittal (b), and transverse (c) sections.

acute and chronic inflammation with fibrosis. No evidence of malignancy or xanthogranulomatous inflammation was seen.

\section{Discussion}

\section{Xanthogranulomatous inflammation in the genito-uri- nary tract}

Xanthogranulomatous inflammation, seen more commonly in other organs such as kidneys and gall bladders is rarely seen in the prostate. Prostatic abscess resulting as a result of xanthogranulomatous prostatitis is even more uncommon: so far only one case has been reported in the literature [2]. Different types of granulomatous inflammation have been described but the exact aetiology of xanthogranulomatous prostatitis is unknown. There are isolated case reports of simultaneous xanthogranulomatous inflammatory affections of kidneys and prostate [3].

In some cases the differential diagnosis could include prostate cancer [4-6]. Diffusion weighted MRI scan appearances of prostatic abscesses have been described; although the clinical implication in treatment of large abscesses appears to be limited, its use in differentiating smaller lesions
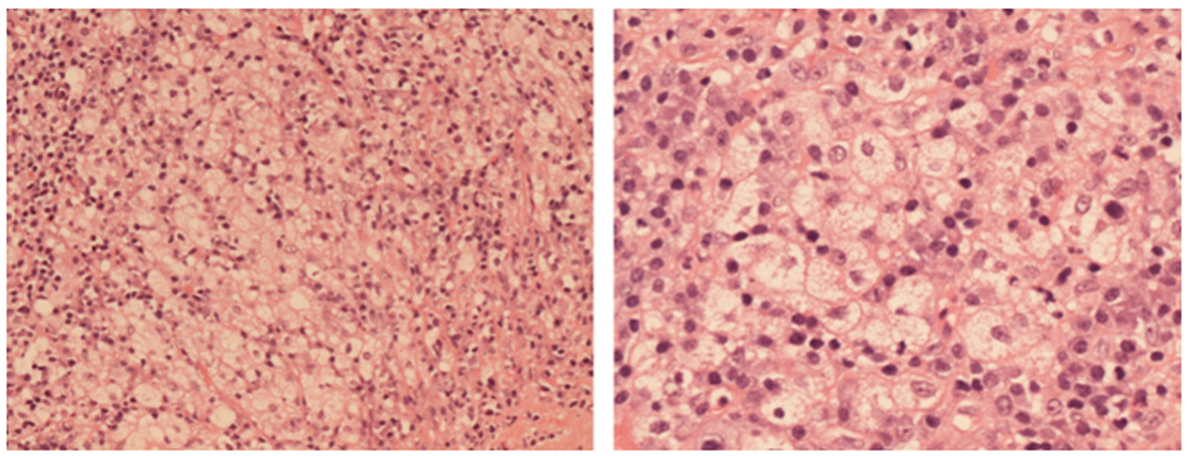

Figure 2. Histological features of Xanthogranulomatous prostatitis from the resected specimen showing fat-laden macrophages. 


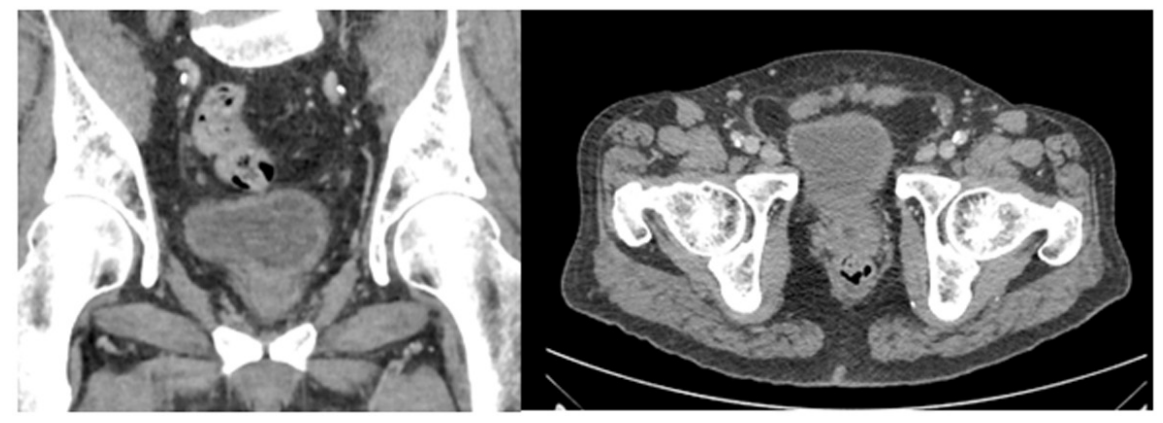

Figure 3. CT appearance after resolution of abscess.

mimicking prostate cancer may be of some use [7]

Xanthogranulomatous orchitis has been reported in literature [8]; with one report of orchitis following intravesical BCG for bladder cancer [9]. Xanthogranulomatous funiculitis and epididymitis have been reported to be rare [10]; one case report mentions evidence of colonies of actinomyces [11]. Differential diagnosis would include other lesions rich in macrophages, such as malakoplakia. In our case, the patient subsequently developed epididymo-orchitis, but the histological findings showed fibrosis due to acute and chronic inflammation only.

There are reports of urinary bladder involvement [12] and rare reports of similar lesions affecting corpus cavernosum [13]. Fistula formation has been reported as a complication of xanthogranulomatous inflammation in the kidney [14], as well as after TURP of a previously undiagnosed xanthogranulomatous prostatitis [15]. Female genito-urinary organs may also be affected [16].

\section{Prostatic abscess}

It was believed that prostatic abscesses had become uncommon due to increased use of antibiotics and decreased incidence of gonococcal infections [17, 18]. However, in patients with diabetes, chronic renal failure, and those with immunosuppression, this diagnosis should be always borne in mind [19], in the event of non-resolution of a urological sepsis. Transrectal prostatic biopsies, instrumentation of lower urinary tract, community acquired MRSA infections are important likely causes leading to a change in the aetiology of prostatic abscess compared to a couple of decades ago $[20,21]$. The causative organism could be E. coli, staph aureus, but community acuired MRSA have been increasingly reported in recent times [21, 22]. In our patient, the likely contributing factors were diabetes, use of immuno-suppressants as well as repeated urethral catheterisation.

Clinical examination, TRUS [23], MRI and CT scans can all be helpful in confirming the anatomical extent of the diagnosis, however prompt drainage of the abscess either by transurethral route or percutaneous/transrectal route is essential for rapid resolution of the associated morbidity. Most series of prostatic abscesses described in the literature have cited drainage of scant amounts of pus. In our case, copious amount of pus was drained; this may have been due to the fact that the diagnosis was made after 4 weeks of presentation with signs of sepsis. Probably an earlier urological referral might have led to a more expeditious diagnosis and resolution.

As far as route of drainage of prostatic abscess is concerned, one study has compared the efficacy of transurethral drainage with percutaneous drainage [24] and found a $22 \%$ incidence of recurrence of the abscess with the latter approach. However, in their large series of 62 cases over a 16 year period, by Meshref et al have reported effective use of Trans-Rectal Ultrasound (TRUS) in helping to drain these abscesses under local anaesthesia [23]. Another study cites the use of transrectal, wide bore needle aspiration using a proctoscope and simultaneous urethroscopic viewing [19]. Conservative management has a much worse outcome and antibiotics alone should not be relied upon for treatment.

\section{Conclusion}

It is generally acknowledged that drainage of prostatic abscesses can be done either by transurethral resection or by transrectal route, supplemented by appropriate antibiotic therapy. The exact method of drainage would be decided by the patient's age, symptoms and the size and location of abscess(es).

Xanthogranulomatous prostatitis is a benign but uncommon condition; and prostatic abscess occurring as a result is even rare. There is as yet no evidence of exact aetiology of this type of inflammation affecting various organs of the body, and immunosuppression, diabetes, chronic renal failure have been reported to be important pre-disposing factors. It has to be remembered that lesions due to xanthogranulomatous inflammation may mimic malignancy in the prostate and other genito-urinary organs.

\section{Conflict of Interest}

None declared. 


\section{References}

1. Cozzutto C, Carbone A. The xanthogranulomatous process. Xanthogranulomatous inflammation. Pathol Res Pract. 1988;183(4):395-402.

2. Valsangkar RS, Singh DP, Gaur DD. Xanthogranulomatous prostatitis: Rare presentation of rare disease. Indian J Urol. 2012;28(2):204-205.

3. Tobian AA, Ober SK. Dual perinephric and prostatic abscesses from methacillin-resistant Staphylococcus aureus. South Med J. 2007;100(5):515-516.

4. Srigley JR. Benign mimickers of prostatic adenocarcinoma. Mod Pathol. 2004;17(3):328-348.

5. Lee HY, Kuo YT, Tsai SY, Li CC, Wu WJ, Huang CH, Juan YS. Xanthogranulomatous prostatitis: a rare entity resembling prostate adenocarcinoma with magnetic resonance image picture. Clin Imaging. 2012;36(6):858860.

6. Murugan P, Brown RE, Zhao B. Nonspecific granulomatous prostatitis with prostatic adenocarcinoma. Indian $\mathrm{J}$ Pathol Microbiol. 2010;53(1):152-154.

7. Singh P, Yadav MK, Singh SK, Lal A, Khandelwal N. Case series: Diffusion weighted MRI appearance in prostatic abscess. Indian J Radiol Imaging. 2011;21(1):4648.

8. Al-Said S, Ali A, Alobaidy AK, Mojeeb E, Al-Naimi A, Shokeir AA. Xanthogranulomatous orchitis: review of the published work and report of one case. Int J Urol. 2007;14(5):452-454.

9. Hill JR, Gorgon G, Wahl SJ, Armenakas NA, Fracchia JA. Xanthogranulomatous orchitis in a patient with a history of instrumentation and bacillus Calmette-Guerin therapy. Urology. 2008;72(2):461 e411-463.

10. Kang TW, Lee KH, Piao CZ, Yun KJ, Joo HJ, Park KS, Choi YD, et al. Three cases of xanthogranulomatous epididymitis caused by E. coli. J Infect. 2007;54(2):e69-73.

11. Nistal M, Gonzalez-Peramato P, Serrano A, Regadera J. Xanthogranulomatous funiculitis and orchiepididymitis: report of 2 cases with immunohistochemical study and literature review. Arch Pathol Lab Med. 2004;128(8):911-914.
12. Fornari A, Dambros M, Teloken C, Hartmann AA, Kolling J, Seben R. A case of xanthogranulomatous cystitis. Int Urogynecol J Pelvic Floor Dysfunct. 2007;18(10):1233-1235.

13. Seo Y, 3rd, Jo HJ, Rim JS. Xanthogranulomatous inflammation of corpus cavernosum. J Sex Med. 2007;4(6):1763-1765.

14. Majeed HA, Mohammed KA, Salman HA. Renocolic fistula as a complication to xanthogranulomatous pyelonephritis. Singapore Med J. 1997;38(3):116-119.

15. Zaber K, Al-Bareeq R. Xanthogranulomatous prostatitis causing entero-vesical fistula. Bahrain Medical Bulletin. 2004;26(4) pp 165-166.

16. Ladefoged C, Lorentzen M. Xanthogranulomatous inflammation of the female genital tract. Histopathology. 1988;13(5):541-551.

17. Jacobsen JD, Kvist E. Prostatic abscess. A review of literature and a presentation of 5 cases. Scand J Urol Nephrol. 1993;27(2):281-284.

18. Dajani AM, O'Flynn JD. Prostatic abscess. A report of 25 cases. Br J Urol. 1968;40(6):736-739.

19. Ali E, Badr M, Nafadi M. A retrospective study of 14 cases diagnosed with prostatic abscess. European urology. 2003;2(1):16.

20. Flannery MT, Humphrey D. Case report of a prostatic abscess with a review of the literature. Case Rep Med. 2012;2012:430657.

21. Pierce JR, Jr., Saeed Q, Davis WR. Prostatic abscess due to community-acquired methicillin-resistant Staphylococcus aureus. Am J Med Sci. 2008;335(2):154-156.

22. Park SC, Lee JW, Rim JS. Prostatic abscess caused by community-acquired methicillin-resistant Staphylococcus aureus. Int J Urol. 2011;18(7):536-538.

23. Meshref A, Aboul-Ela A, Torky M, Morsy A. The role of TRUS in the diagnosis and management of prostatic abscess. European urology Supplements. 2007;6(2):70.

24. Lee SH, Park KK, Chung MS, Han HH, Lee DH, Chung $\mathrm{BH}$. Comparison of prostatic abscess treatment: is transurethral resection of prostatic abscess more effective than needle aspiration? European urology Supplements. 2011;10(2):193-194. 